\title{
Correction to: Characterization of the chicken $T$ cell receptor $\gamma$ repertoire by high-throughput sequencing
}

\author{
Tongtong Zhang, Qian Li, Xiaoqing Li, Li Kang, Yunliang Jiang ${ }^{*}$ and Yi Sun*
}

\section{Correction to: BMC Genomics 22, 683 (2021) https://doi.org/10.1186/s12864-021-07975-7}

Following publication of the original article [1], an error was identified in the Methods section.

It currently reads:

In "Library preparation, HTS and data analysis" in the Methods section, the description "Overlapping pairedend reads from the 5' RACE-based library were merged with FLASH [20], and these merged sequences were aligned to the germline $\mathrm{V}_{\gamma}$ and $\mathrm{J}_{\gamma}$ segments identified above using a local BLAST program (version 2.2.30) and each sequence was assigned an optimal germline $\mathrm{V}_{\gamma}$ and

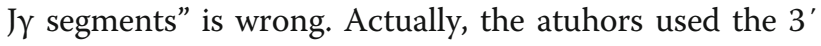
end reads which contain the $\mathrm{C} \gamma$-specific reverse primer for $5^{\prime}$ RACE and $250 \mathrm{bp}$ in length to analyze the optimal germline $\mathrm{V}_{\gamma}$ and $\mathrm{J}_{\gamma}$ segments that participated in $\mathrm{V}_{\gamma}-\mathrm{J}_{\gamma}$ rearrangement. This error does not influence any conclusion of this paper.

It should read:

In "Library preparation, HTS and data analysis" in the Methods section, use "The 3' end reads which contain the $\mathrm{C} \gamma$-specific reverse primer for $5^{\prime}$ RACE and $250 \mathrm{bp}$ in length were aligned to the germline $\mathrm{V}_{\gamma}$ and $\mathrm{J}_{\gamma}$ segments identified above using a local BLAST program (version 2.2.30) and each sequence was assigned an optimal germline $\mathrm{V}_{\gamma}$ and $\mathrm{J} \gamma$ segments."

All the changes requested are implemented in this correction and the original article [1] has been corrected.

Published online: 29 November 2021

\section{Reference}

1. Zhang T, Li Q, Li X, et al. Characterization of the chicken T cell receptor $Y$ repertoire by high-throughput sequencing. BMC Genomics. 2021;22:683. https://doi.org/10.1186/s12864-021-07975-7. licence and your intended use is not permitted by statutory regulation or exceeds the permitted use, you will need to obtain permission directly from the copyright holder. To view a copy of this licence, visit http://creativecommons.org/licenses/by/4.0/ The Creative Commons Public Domain Dedication waiver (http://creativecommons.org/publicdomain/zero/1.0/) applies to the data made available in this article, unless otherwise stated in a credit line to the data. 